\title{
MODIFICAÇOESS HISTOLÓGICAS E HISTOQUIMMICAS DO CORPO GORDUROSO DE RAINHAS DE Atta sexdens rubropilosa FOREL (HYMENOPTERA, FORMICIDAE) DURANTE O PRIMEIRO CICLO REPRODUTIVO* .
}

\section{HISTOLOGICAL AND HISTOCHEMICAL MODIFICATIONS \\ OF THE FAT BODY OF Atta sexdens rubropilosa FOREL (HYMENOPTERA, FORMICIDAE) DURING THE FIRST REPRODUCTIVE CYCLE* .}

Marina A. Staurengo da Cunha ** Carminda da Cruz Landim***

\section{INTRODUÇĀO}

O corpo gorduroso dos insetos é um tecido difuso e irregular, que tem como uma de suas funções a de armazenar reservas alimentares. Segundo CHAPNIAN (1) este tecido consiste de uma massa frouxa de células arranjadas em cordões ou lâminas. Essa massa contém essencialmente um único ti. po de célula, funcionalmente diver sificada e capaz de armazenar glicogênio, lipídeos e proteínas (9). Estas células de reserva também chamadas trofócitos ou adipócitos podem estar associadas à tipos celulares especializados, tais como: células de urato, oenócitos e micetócitos (6).

A quantidade e a natureza das reservas alimentares dentro do corpo gorduroso varia sob condições internas ou ambientais diversas. Assim o ciclo de muda, o estado nutricional e o estágio de desenvolvimento do inseto, entre outras coisas, podem influenciar sua histofisiologia.

Muitos estudos ao nivel de microscopia óptica mostraram as transformações que ocorrem no corpo gorduroso durante o crescimento e a metamorfose, durante a alimentação e jejum em larvas de Drosophila (4), em larvas de Calpodes ethlius (12) em larvas de Philosamia cynthia (5). Na larva, o corpo gorduroso desempenha importante papel no metabolismo interme

* Pesquisa financiada com auxilio do CNPq (Proc. 2222.0416/78).

* Professor Assistente Doutor junto ao Departamento de Biologia Instituto de Biociencias - UNESP, 13.500 - Rio Claro - SP.

* * Professar Titular junto ao Departamento de Biclogia, Instituto de Biociências UNEEP, 13.500 - Rio Claro - SP. 
diário, mas poucos estudos estão disponíveis em insetos adultos apesar de sua importância na produção de ovos, diapausa e vốo.

Estudos da morfologia e função do corpa gorduroso e células associadas em Atta estão sendo iniciados, com o objetivo de determinar quais produtos são mobilizados pelo inseto durante a vida adulta $e$, qual a relação com o desenvolvimento do sistema reprodutor em desenvolvimento. No caso específico tratase justamente do início da fase de postura por parte da rainha.

\section{MATERIAL E MÉTODOS}

lçás de Atta sexdens rubropilosa foram coletadas a intervalos: durante a revoada (considerado 1 dia), 5, 18, 35, 60 e 130 dias após a revoada e nid ificação em condições naturais.

Em seguida foram dissecadas em solução fisiológica para insetos. Porçóes do corpo gorduroso foram retiradas e fixadas separadamente em Car. noy, Bouin e formol-cálcio de Baker. A desidratação, diafanização e inclusão em parafina foram efetuadas segundo a técnica rotineira. Seç̧ões de 7 ; $2 \mathrm{~m}$ foram submetidas a uma variedade de técnicas de coloração. A técnica estândar de hematoxilina Delafield-eosina foi usada para exame histológico. Testes histoquímicos foram realizados de acordo com o apresentado por PEARSE (11), por LISON (8) e por LANGÉRON (7).

Para demonstração de proteínas foi utilizada a reação de ninhidrinaSchiff segundo Yazuma e Ichikawa. A reação do ácido periódico-Schiff segundo McMannus foi usada para demonstrar a existência de carbohidratos. Prevenção da reação de PAS acima, por meio da acetilação, foi feita afim de verificar a natureza carbohidrática dos grupos reagentes. Secções controles submetidas separadamente, à digestão pela amilase salivar e coloraçăo pelo Carmin de Best foram usadas para demonstração do glicogênio. Lipídeos foram demonstrados pelo método do Sudan Black $B$ e a coloração com verde metila-pironina com e sem ribonuclease para RNA.

\section{RESULTADOS}

O presente estudo referese essencialmente ao corpo gorduroso localizado no abdome, onde se apresenta sob a forma de uma massa de células prendendo-se firmemente aos ovários e demais órgåos. As células intumescidas devido ao acúmulo de reservas mantém-se unidas devido à grande quantidade de ramos traqueais entre elas. Este corpo gorduroso é formado por um tipo único de célula - o trofócito.

$\hat{A}$ idade de 1 dia o corpo gorduroso apresenta-se muito compactado e por isso as células exibem forma poliédrica (Fig. 1A). Como se trata de um tecido de reserva, as células apresentam-se cheias de grãos, gotas e vacúolos de vários tamanhos. Pela figura $\uparrow$ nota-se que estas células aumentam de volume até aos 35 dias (Figs. 1A e 1D), daí diminuindo (Figs. 1E e 1F) sendo que aos 60 dias exibem um aspecto de degeneração. Aos 130 dias, as células graindes praticamente desapareceram restando apenas traquéias que se asse- 
melham a fios de sustentação e, algumas célulias pequenas com aspecto flácido.

O teste do PAS e os testes controles revelaram a existência de material PASt assim distribuído: em insetos de 1 dia o material apresenta-se sob a forma de pequenas gotas, principalmente na periferia da célula, mas aos 5 dias a célula cresce e este material aparece com aspecto amorfo ocupando todo o interior da célula, com exceção da periferia onde aparece um cortex preenchido por pequenas gotas PAS-- (provavelmente lipídeos). Os controles (digestão pela amilase salivar e prevençăo da reaçăo por acetilação) indicam que o material PAS+ provavelmente é constituído por carbohidratos associados a glicoproteínas. O teste do Carmin de Best confirmou que o glicogênio em insetos de 1 dia, localiza-se na periferia e aos 18 dias evidenciou que existem dois tipos de células; as que possuem grandes gotas que não se coram e pouco glicogênio no centro, e as que possuem pequenas gotas, não coradas, espalhadas e glicogênio entre elas.

Aos 18 dias todas essas reaçōes săo fracamente positivas mas entre 5 e 18 dias, a célula continua o crescimento, coincidindo este com um acúmulo de lipídeos e decréscimo de material proteíco.

Aos 35 dias a reação do PAS após acetilaçăo é negativa na periferia. da célula ( $F i g .2 B$ ) evidenciando agora, sem dúvida, que os carbohidratos estão novamente localizados nesta região. $O$ controle pela amilase (Fig. 2D) e o teste pelo Carmin de Best revelaram que grande parte deste material é glicogênio. Aos 60 dias há um decréscimo deste material sendo que aos 130 dias, localiza-se na periferia em pequena quantidade.

Supomos serem de lipideos as gotas não coradas apresentadas pelas células em todas as idades examinadas, uma vez que eles devem ter sido extraídos devido aos procedimentos histoquímicos empregados. Este material aparece em todas as fases de desenvolvimento do corpo gorduroso. Em içás de 5 dias, (Fig. 3A) os grånulos de lipídeos estâo concentrad os mais ná periferia da célula. Aos 18 (Fig. $3 \mathrm{C}$ ) e 35 dias são encontrados numa distributção mais homogênea pelo interior da célula. Pequena quantidade de grânulos de lipideos com distribuiçăo homogênea caracterizam o corpo gorduroso de içás de 60 a 130 dias.

$O$ teste da ninhidrina-Schiff revelou que em içás de 1 a 5 dias o material positivo acumula-se no bordo externo da célula (Fig. 3B). Aos 18 dias. esta reação é fracamente positiva exibindo-se pequena quantidade de grăos positivos mais para o interior da célula (Fig. 30). Novamente aos 35 dias há um acúmulo de material positivo no bordo da célula, e aos 60 e 130 dias toda célula contém este material, em quantidade média, espalhada pelo interior. Este teste indica a presença de agrupamentos amina, e portanto proteínas em geral.

A coloração pelo verde metila-pironina revelou aos 5 dias a presença de um núcleo alongado e comprimido pelas reservas, tomando, no corte, a forma de um fio irregular, ramificado nas extremidades. Esta forma também foi confirmada através do exame ultraestrutural destas células (13). Pequena quantidade de granulaçåo fina corada pela pironina aparece espalhada pelo citoplasma entre os vacúolos abundantes (Fig. 4A). Aos 


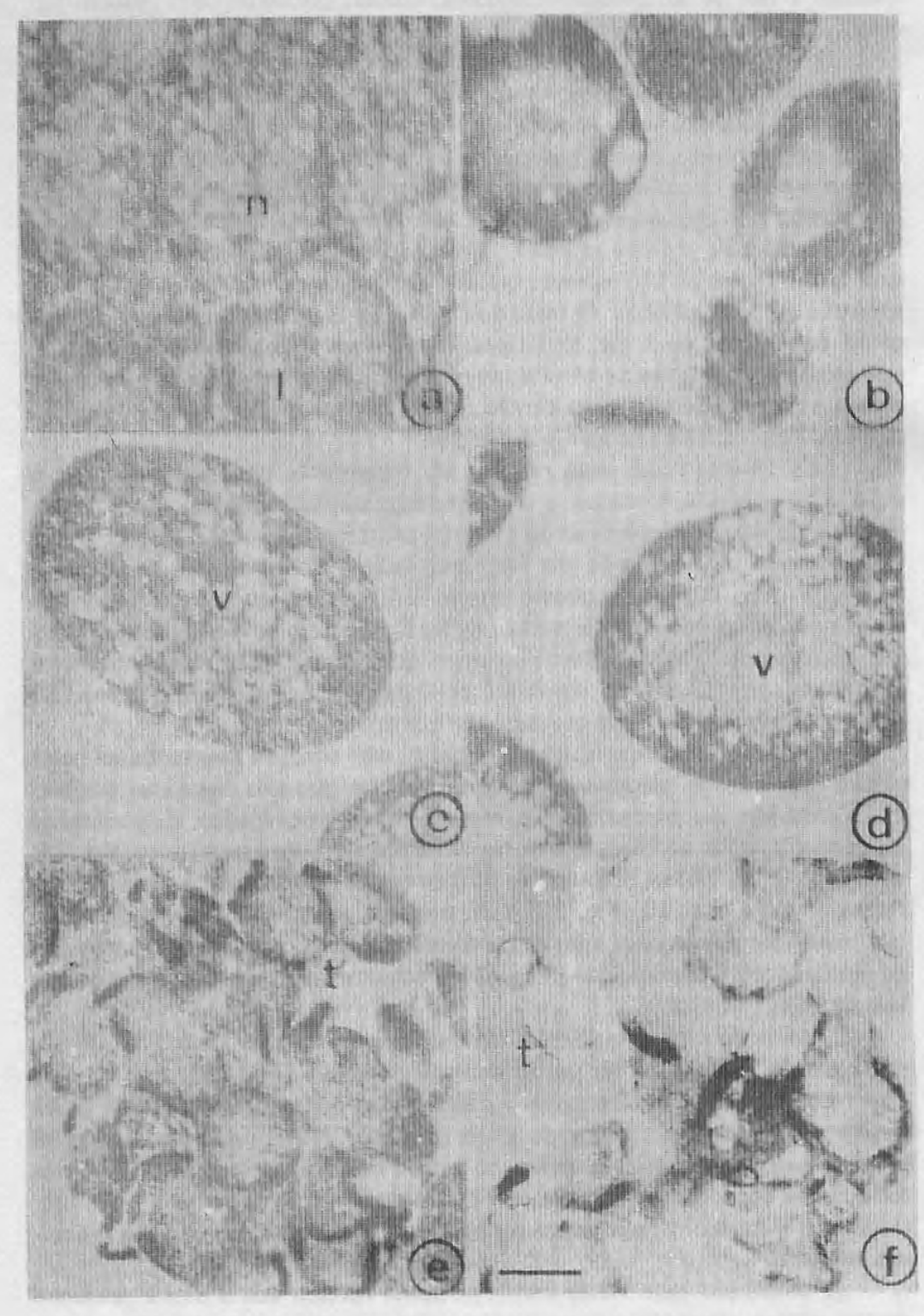

FIG. 1 - Células do corpo gorduroso de Atta sexdens rubropilosa, coradas com HE, tendo respectivamente 1, 5, 18, 35, 60 e 130 dias apús a revoada. Notar em A. o núcleo (n) na forma de filamento longo. Lipídeos (1), vacúolos (v) e traquefas (t). Escala: $1 \mu \mathrm{m}$. 


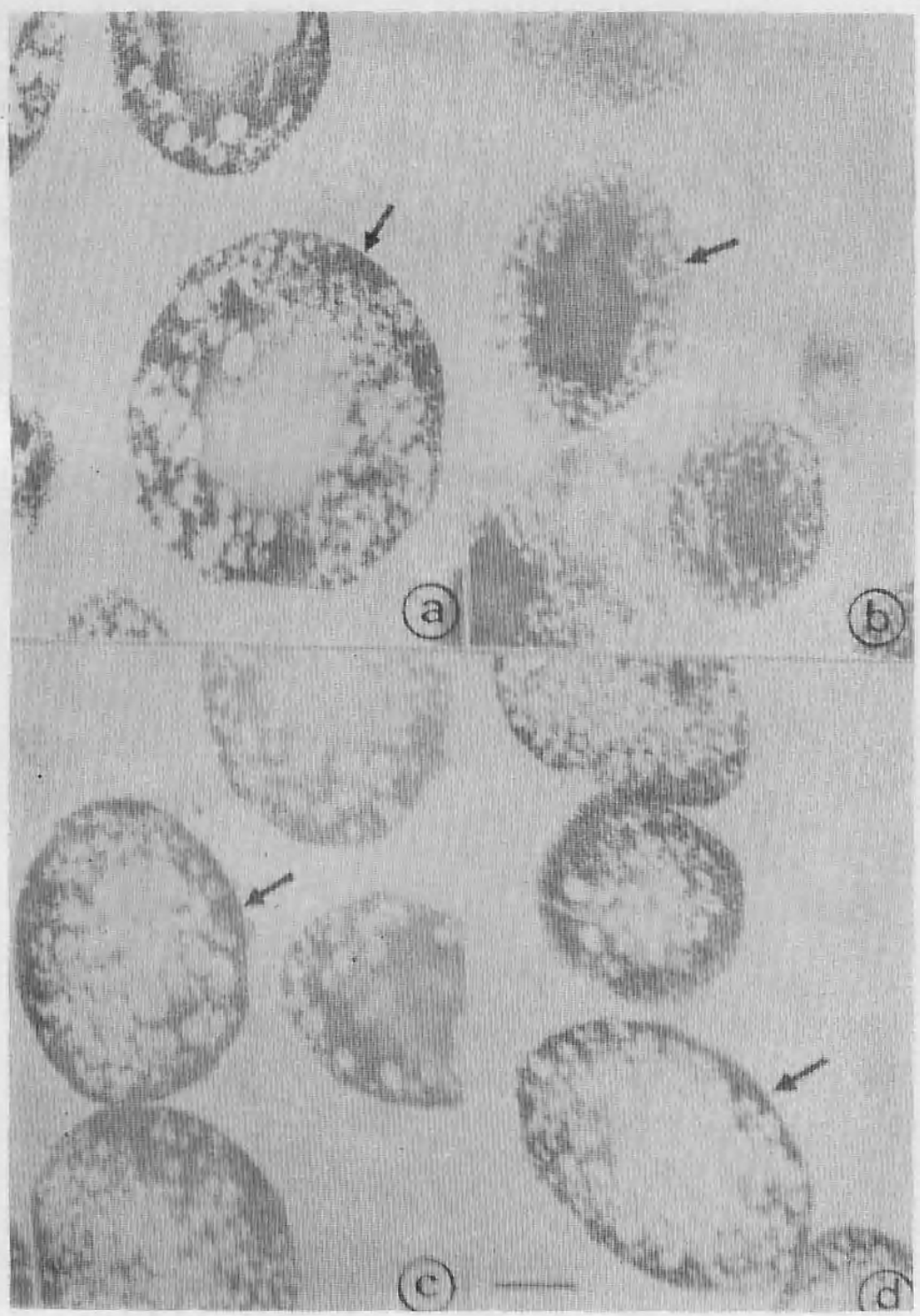

FIG. 2 - Células do corpo gorduroso aos 35 dias, submetidas aos seguintes tratamentos. A - PAS; B - PAS + acetilação: C - PAS + acetilação + saponificação; D - PAS + amilase salivar. As setas indicam reação positiva em $A$ e $C$, e reação negativa em $B$. Em $\mathrm{D}$ pequena quantidade de glicogénio na periferia. Escala: $1 \mu \mathrm{m}$. 


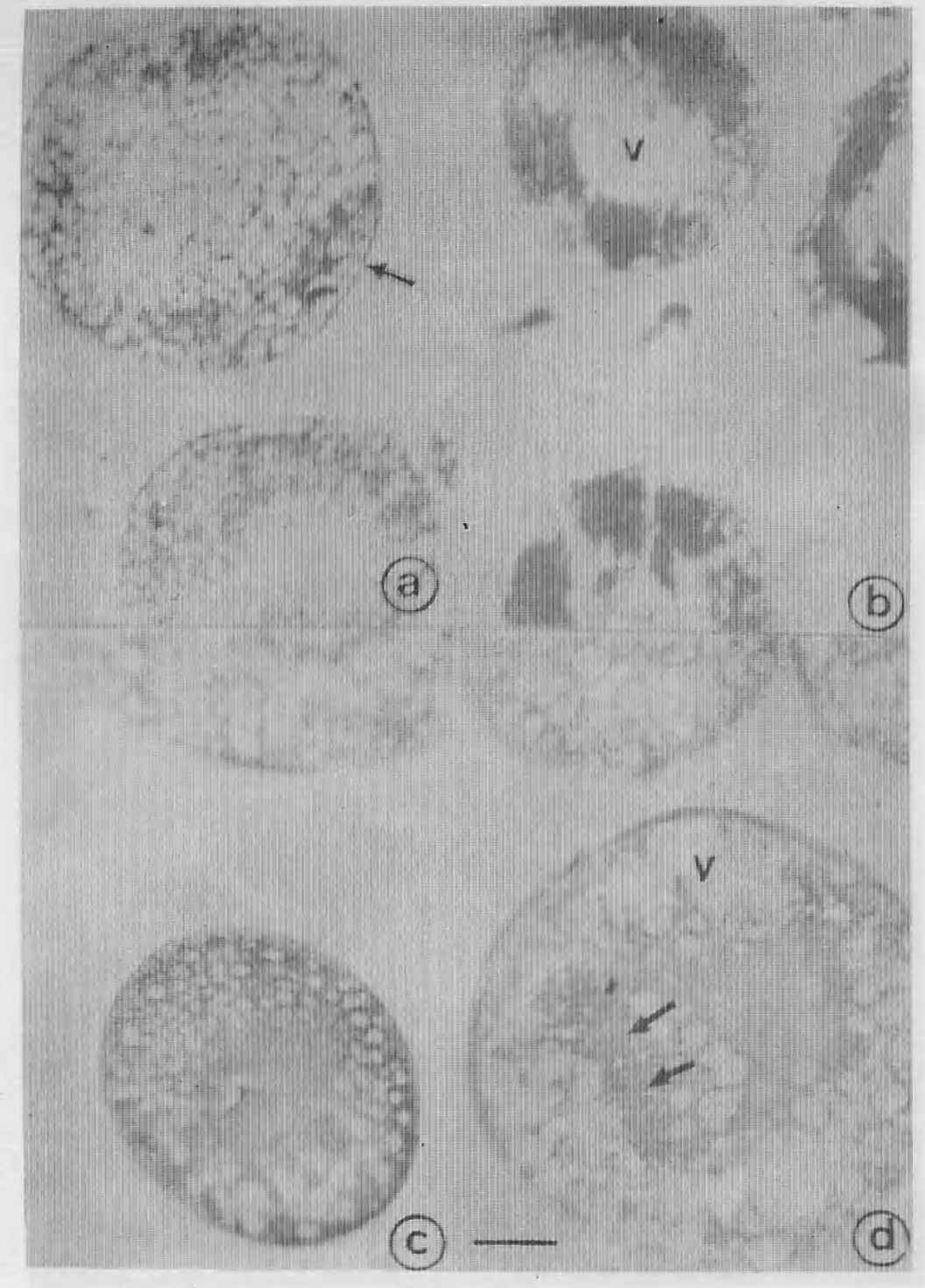

FIG. 3 - Células do corpo gorduroso, sendo: A e C, com 5 e 18 dias, coradas por Sudan Balck $B$. A seta em $A$ indica reação positiva intensa na periferia. Figuras $B$ e $D$ com 5 e 18 dias; coradas pela Ninhidrina-Schiff. A seta indica em B, reação + mais intensa no bordo da célula enquanto em $D$ ela aparece mais centralmente. Vacúolos (v). Escala: $1 \mu \mathrm{m}$. 
18 dias o núcleo aparece localizado mais perifericamente, e as células apresentam um halo de material homogêneo pironinófilo rodeando grande quantidade de vacúolos na parte central. Aos 35 dias desaparece o vacúolo maior central e o halo periférico restando apenas vacúolos pequenos. É aos 60 dias que aparece no citoplasma uma grande quantidade de yranulações coradas pela pironina (Fig. 4B).

Hemócitos associados aos trofócitos (Figs. 4A, 4C e 4D) apareceram em todas as idades, mas a partir dos 60 dias é que se tornam mais abundantes,

A tabela I resume as informações sobre a intensidade das reações apresentadas pelos trofócitos, face aos diversos testes histoquímicos empregados.

\section{DiSCUSSÃO E CONCLUSÖES}

Os trofócitos de 1 dia de idade contém material PAS+ (polissacarídeos e glicoproteínas) na forma de gotas, material ninhidrina-Schiff e glicogênio principalmente na periferia da célula. Concomitantemente ao crescimento da célula nota-se, aos 5 dias, um acúmulo deste material mais centralmente e grande quantidade de gotas de lipídeos espalhados pelo citoplasma.

Aos 18 dias estas células atingem seu tamanho máximo coincidindo com o aumento do acúmulo de lipídeos. Entre 18 e 35 dias as células começam a diminuir de volume, levando a uma diminuição de material proteíco e lipídeos, e ao aparecimento de um novo estoque de material PASt (glicogêniolo).

As rainhas de Atta sexdens rubropilosa eclodem com o corpo gorduroso muito desenvolvido. As reservas que este contém ainda provém da alimentação larval e são sobras do que náo foi consumido durante a metamorfose. O crescimento das células do corpo gorduroso até 18 dias pode ser devido à alimentação obtida antes da revoada ou remanejamento de reservas acumuladas nos ovócitos que não são postos durante a metamorfose, e da degeneração da musculatura do vỏo.

As reservas do corpo gorduroso, são quase totalmente consumidas até 60 dias após a nidificação e a julgar pelo desenvolvimento do ovário nesse período parecem ser utilizadas na vitelogênese, uma vez que a rainha aparentemente não se alimenta neste período.

Aos 60 e 130 dias há um decréscimo de todo o material PASt restando certa quantidade de proteínas, bem como a presença de grăos coroados pela pironina (provavelmente RNA) principalmente aos 60 dias, Assim, o corpo gorduroso, num período de 130 dias reserva por ordem, polissacarídeos e glicoproteínas, lipídeos, glicogênio e RNA. Aparentemente, acúmuio e descarga das reservas ocorrem ciclicamente. Pelo menos no período exam:nado, foi possivel observar armazenamento e descarga de carbohidratos, seguido de nova fase de armazenamento. Para os lipídeos, foi observado armazenamento e descarga, enquanto os níveis proteicos se mantiveram mais ou menos constantes durante o período estudado. Altos niveis proteícos e de ácidos ribonucleicos também aparecem em rainhas de termitas (3).

Segundo MARICONI (10) a içá, durante cerca de mais ou menos 90 dias após a fundação do novo ninho põe dois tipos de ovos, os ovos alimen- 


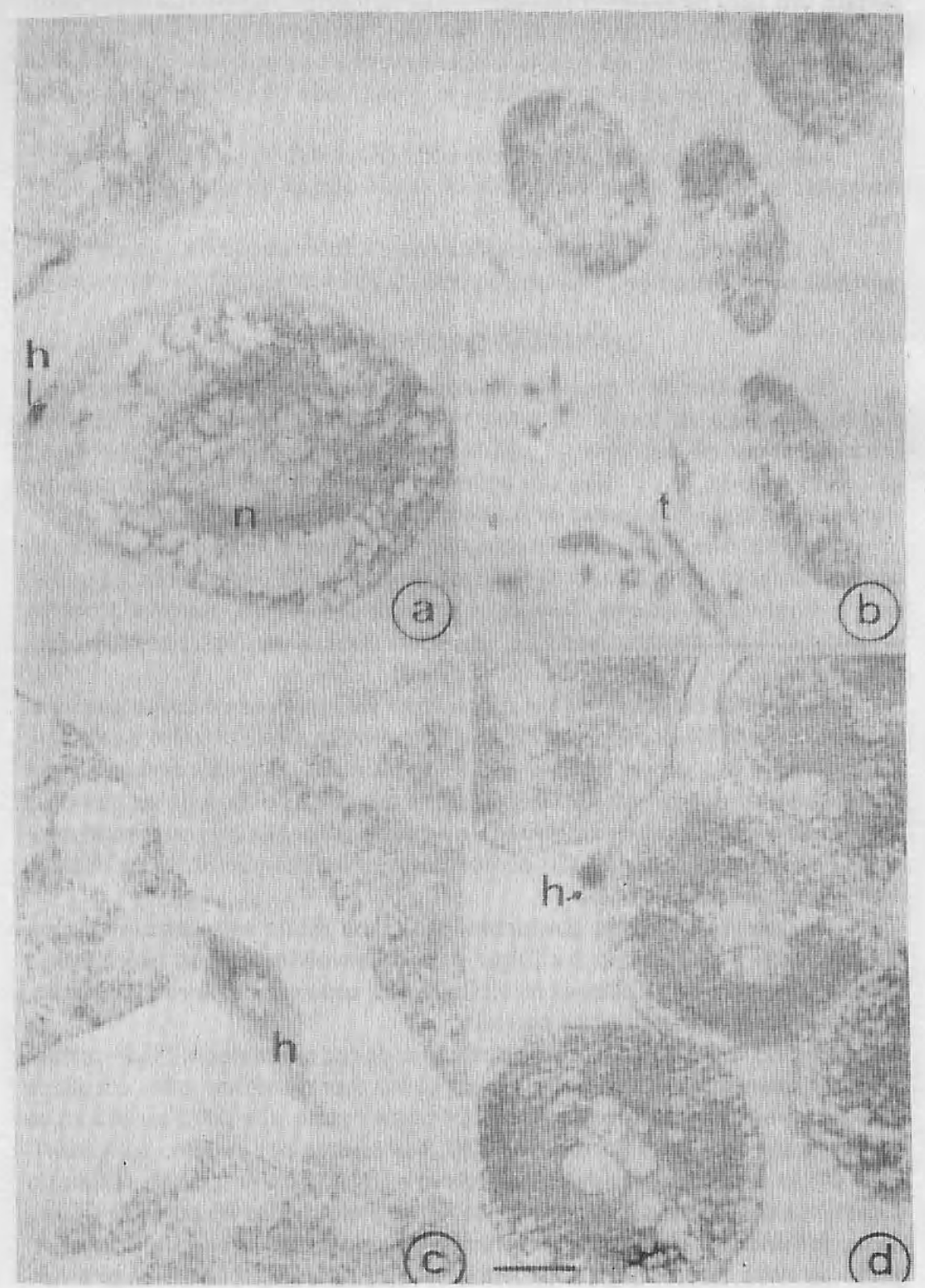

FIG. 4 - Células do corpo gorduroso, sendo: $A$ e $B$ ( 5 e 60 dias) tratadas pelo verde metila-pironina. Em A, trofócito com núcleo (n) em forma de filamento, e em $A, C$ e D, hemócitos (h) associados aos trofócitos. Traqueías (t). Escala: $1 \mu \mathrm{m}$. 


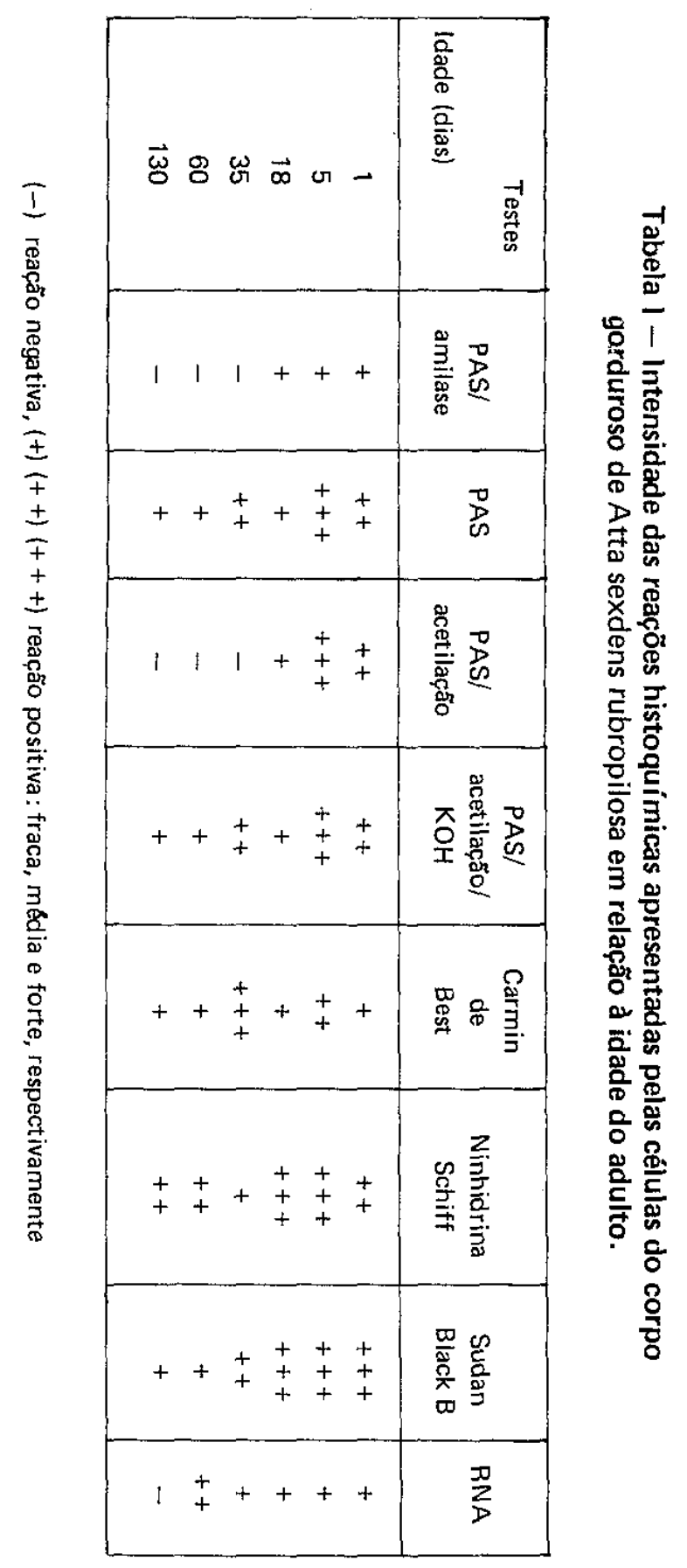


tares e ovos funcionais. Alimenta-se a si prápria e à prole com os ovos de "alimentação" que diferem bastante dos ovos normais. Após esse período põe apenas ovos funcionais.

O maior crescimento dos ovários como demonstrado por STAURENGO DA CUNHA et alii (14) ocorre, nas içás, entre 35 a 60 dias, após a fundação do ninho, enquanto as células do corpo yorduroso crescem entre 18 e 35 dias, principalmente por acúmulo de lipídeos. CRUZ-LANDIM (2) também encontrou que os lipídeos constituem a reserva mais importante do corpo gorduroso de operárias adultas de Apis mellifera aćansonii.

Portanto, pode-se supor, que de inicio, até 18 dias ambos crescem por absorção de material da hemolinfa (conseguido graças à digestão dos ovos de alimentação) e após isso, os ovários crescem às custas do corpo gorduroso. Isto é confirmado pelo fato de encontrarmos aos 60 dias as células do corpo gorduroso completamente degeneradas enquanto os ovários estão no máximo de desenvolvimento.

\section{RESUMO}

Içás coletadas a 1.5, 18, 35, 60 e 130 dias após a revoada e início de nidificação tiveram os corpos gordurosos examinados histológica e histoquimicamente. Estes são formados por um único tipo de célula - o trofócito, que reserva por ordem: polissacarídeos e glicoproteínas, lipídeos, glicogênio, proteínas e RNA. Para carbohidratos foi possível verificar armazenamento, descarga e nova fáse de armazenamento, enquanto para lipídeos foi observado armazenamento e descarga.

PALAVRAS-CHAVE: içá, corpo gorduroso, trofócito, histoloyia, histoquímica.

\section{SUMMARY}

Histological and histochemical observations were made up on the fat body of the ant Atta sexdens rubropilosa, 1, 5, 18, 35, 60 and 130 days after the nuptial flight and foundation of a new nest. The fat body is formed by a single type of cell-the trophocyte, which reserves in order: polysaccharides and carbohydrates containing proteins, lipids, glycogen, proteins and RNA. For carbohydrate it was possible to verify storage, discharge and new phase of storage, while for lipds only storage and discharge were observed.

KEY WORDS: ant queen, fat body, trophocyte, nistology, histochemistry.

\section{RÉSUMÉ}

Reines de Atta sexdens rubropilosa ont été recoltées aprés 1, 5, 18 , 35,60 et 130 jours du vol nuptial, et du début de la nidification. Des analyses histologiques et histoquimiques ont été effectuées sur le tissu adipeux. 
Les résultats ont mis en évidence un type cellulaire unique, le trophocyte. Cette cellule fait le stockage des polysacharides et glycoproteines, lipides, glycogéne, protéines et RNA. En ce qui concerne les polysacharides nous avous pu montrer une décharge cellulaire placée entre deux phases de stockage. Cependant, pour le lipides nous avons observé une phase de stockage suivie d'une déchargement de ces produits cellulaires.

MOTS CLÉS: fourmi, Atta, tissu adipeux, histologie, histoquimie.

\section{BIBLIOGRAFIA}

(1) CHAPMAN, R,F. The insects: structure and function. London, The English Univ. Press Ltd., 1979. 819p.

(2) CRUZ-LANDIM, C. Estudo do corpo gorduroso de Apis mellifera adansonii ao microscópio óptico e eletrônico. Anais do III Congr. Bras. Api., 137-147, 1975.

(3) GABE, M. \& NOIROT, C. Particularités histochemiques du tissu adipeux royal des termites. Bull. Soc. Zool., (Paris), 85:376-382, 1960.

(4) GAUDECKER, B. Uber den Formwechsel einiger Zellorganeile bëider Bildung der Reservestoffe in Fettkorper von Drosophila Larven. Z. Zellforsch. mikrosk. anat., Berlin, 61:56-95, 1963.

(5) ISHIZAKI, H. Electron microscopic study of changes in the subcellular organization during metamorphosis of the fat body cell of Philosamia cynthia ricini (Lepidoptera). J. Insect Pnysiol., Londres, 11.345-855, 1965.

(6) JONES, J.C. The circulatory system if insects. Springfield, Charles C. Thomaz Pulb., 1977. 255p.

(7) LANGÉRON, M. Précis de microscopie. Paris, Masson et Cie, 1943. $1205 \mathrm{p}$.

(8) LISON, L. Histochimie et cytochimie animales. Paris, Gauthier Villars Ed., 1953. 607p.

(9) LOCKE, M. \& COLLINS, J.V. The structure and formation of protein granules in the fat body of an insect. J. Cell Biol., Nova York, 26(3). 857-884, 1965.

(10) MARICONI, F.A.M. As saúvas, São Pasilo, Edit. Agrọnómica Ceres, 1970. 167p.

(11) PEARSE, A.G.E. Histocnemistry - tneoretical and applied. London, J. \& A. Churchill Ltd. 1960. 998p.

(12) SMITH, D.S. Insect cells: their structure and function. Edinburg, Oliver \& Boyd Ltd., 1968. 372p.

(13) STAURENGO DA CUNHA, M.A. \& CRUZ-LANDIM, C. O corpo gorduroso de rainhas de Atta sexdens rubropilosa Forel (Hymenoptera Formicidael. Anais do VI Colóquio Bras. de Microscopia Eletrônica, S. Paulo, 104-105, 1978.

(14) STAURENGO DA CUNHA, M.A.; SILVA DE MORAES, R.L.M. 
\& CRUZ-LANDIM, C. Estágios do desenvolvimento ovariano em Atta sexdens rubropilosa Forel (Hymenoptera: Formicidae). No prelo, 1982. 